\title{
Increasing the attractiveness of tourism-related Facebook pages based on emotion analysis of user comments
}

\author{
Ayako Sawada (Community and Culture Department, Hokuriku Gakuin Junior College, sawada@hokurikugakuin.ac.jp) \\ Taketoshi Yoshida (School of Knowledge Science, Japan Advanced Institute of Science and Technology, yoshida@jaist.ac.jp)
}

\begin{abstract}
The percentage of people using social network services (SNSS) exceeds $60 \%$ in Japan; SNSs are being used by people of various age groups. Recently, the number of companies that use Facebook Pages to advertise their activities and the number of organizations that use them to disseminate information have been increasing. In tourism, disseminating local information on Facebook Pages and increasing the attractiveness of the pages are expected to lead to the promotion of regional tourism industries. In this study, the current state of the use of tourism-related Facebook Pages was examined. The engagement rate and the number of fans were used as an indicator of the attractiveness of Facebook Pages. An increase in the attractiveness of Facebook Pages was examined through emotion analysis of user comments.
\end{abstract}

\section{Keywords}

Facebook page, regional development, user comments, emotion analysis, engagement rate

\section{Introduction}

Along with the spread of smartphones, the number of people using social network services (SNSs) has been increasing. The number of monthly active users of Facebook worldwide (those who use Facebook one or more times per month) reached 2.01 billion as of 30 September 2017 [Facebook, 2017]. In addition, it is reported that the number of monthly active users of Instagram is 0.8 billion (as of 26 September 2017) [Instagram, 2017], that of Twitter is 0.313 billion (as of 30 June 2016) [Twitter, 2016], and that of Line is 0.217 billion (as of 31 December 2016) [Line, 2017]. According to the 2015 White Paper on Information and Communications in Japan published by the Ministry of Internal Affairs and Communications [2015], the SNSs used in Japan over the last one year include Line (37.5 \%), Facebook (35.3\%), and Twitter (31.0\%). The number of people using SNSs generally tends to decrease with increasing age: approximately $50 \%$ of people aged 20 or younger, less than 40 $\%$ of people in their 30's and 40's, and more than $20 \%$ of people aged 60 or older use Facebook. It is reported that Facebook is being used by people of various age groups. With this background, a variety of research projects on Facebook have been carried out. Wilson et al. [2012] classified 412 sociology papers on Facebook into five categories: descriptive analysis of users, motivations for using Facebook, identity presentation, the role of Facebook in social interaction, and private information disclosure.

Recently, both the number of companies that use Facebook Pages to advertise their activities and the number of organizations that use them to disseminate information have increased. Ohara et al. [2015] clarified the characteristics of photos that increase the responses of users of Facebook Pages of fastfood companies by principal component analysis. In tourism, disseminating local information on Facebook Pages and increasing the attractiveness of pages are expected to lead to the promotion of regional tourism industries. By multiple regression analysis, Sabate et al. [2014] investigated the factors that increase the attractiveness of Facebook Fan Pages (currently, Facebook Pages) of five travel agencies in Spain using the numbers of "Likes" and comments regarding each post as indices of attractiveness. The results indicate that the number of "Likes" is affected by the presence of video images and photos in the post and that the number of comments is affected by the presence of photos and the time period of posting. However, the methods of using Facebook are rapidly advancing and most recent posts almost always include photos or video images. Lee and Paris [2016] clarified users' emotion status had the significant effect on users' acceptance of social media especially Facebook using the adapted Technology Acceptance Model.

Research on Facebook and its usefulness for those involved in the promotion of regional tourism industries is limited, although how-to books on posting on Facebook Pages [Comnico, 2014] and marketing strategies using Facebook [Saito, 2014] have been published. Consequently, Sawada et al. [2016] analyzed the content of tourism-related posts on Facebook Pages with high attractiveness and clarified the following. The responses of users of Facebook Pages offering information related to Christmas, flowers, and foods were high, whereas those for pages offering information on cultural events tended to be low. The responses of users of Facebook Pages offering real-time information, such as information on the start of the blooming of cherry blossoms, tended to be high. In addition, it was found that the responses of users were affected by the type of photos posted.

To increase the attractiveness of Facebook Pages, the analysis of not only the posts of organizations but also the feelings of users that cause them to post comments need to be clarified. The purpose of this study is to analyze the current state of the 
use of Facebook Pages in tourism in Japan and the sentiments behind the comments on Facebook Pages with high attractiveness, and to clarify the feelings of the users who posted comments and the factors behind the increase in the attractiveness of these pages.

In Section 2, the current state of the use of Facebook Pages offering regional tourism information is analyzed in terms of the number of fans, management, and the responses of users to find the characteristics of Facebook Pages with high attractiveness. In Section 3, user comments on these Facebook Pages are analyzed. In Section 4, the factors behind the increase in the attractiveness of pages are discussed on the basis of the results of analyzing user comments. Section 5 is the conclusion.

\section{Facebook pages in tourism}

Facebook navi (http://f-navigation.jp/) is the only navigation site in Japan recognized by Facebook, Inc. In this study, 842 Facebook Pages registered in the Facebook Page ranking in the travel category of Facebook navi were examined. The data were collected on 10 January 2016. In this section, Facebook Pages offering regional tourism information were selected and the relationship between the number of fans and organization managing the site was clarified. Then, Facebook Pages with high attractiveness were determined on the basis of the responses of users and the number of fans.

\subsection{Contents of Facebook pages}

The authors browsed the 842 target pages in the travel category and classified them depending on their contents. Among the 842 pages, $30 \%$ of the pages are managed by accommodation facilities, $14 \%$ by tourist facilities such as aquariums and museums, $7 \%$ by travel agencies, and $3 \%$ by transportation organizations. Some of these pages offer regional tourism information such as festivals, events, and the start of the autumn foliage season. However, these pages are basically used as a public relations tool of these facilities and organizations.
Other pages disseminate regional tourism information rather than advertising the activities of organizations. The management of these pages varies from companies and individuals to volunteer groups. Twenty-one percent of the pages (178 pages) focus on information about particular regions; $3 \%$ focus on information about specific topics such as one-day hot spring trips, famous places for flowers, and Buddhist statues; and 6 $\%$ focus on information about foreign countries. In this study, we targeted the 178 pages focusing on information about particular regions.

\subsection{Pages offering regional tourism information \\ 2.2.1 Number of fans}

The users clicking the "Like" button of a Facebook Page are registered as fans of the page. The postings on the page appear in the News Feed of the user, and the user can browse the various types of information on a Facebook Page on which they are registered as fans. The number of users who have clicked the "Like" button is "the number of fans". Figure 1 shows the number of fans of the 178 Facebook Pages offering regional tourism information. The number of fans of the top-ranking page exceeds 70,000. There are 19 pages with more than 10,000 fans. There are 143 pages with less than 5,000 fans, and 72 of the 143 pages with less than 1,000 fans. For most of the pages, the number of fans is limited and the number of users browsing the pages offering regional tourism information is low, suggesting that the effect of these pages on the promotion of regional tourism industries is limited.

\subsubsection{Management}

Figure 2 (top row) shows the classification of the management of the 178 pages offering regional tourism information. Among the pages, 37, 24, and $9 \%$ of the Facebook Pages are managed by individuals, private companies, and local governments, respectively. Others include regional tourist associations in the form of general incorporated associations,

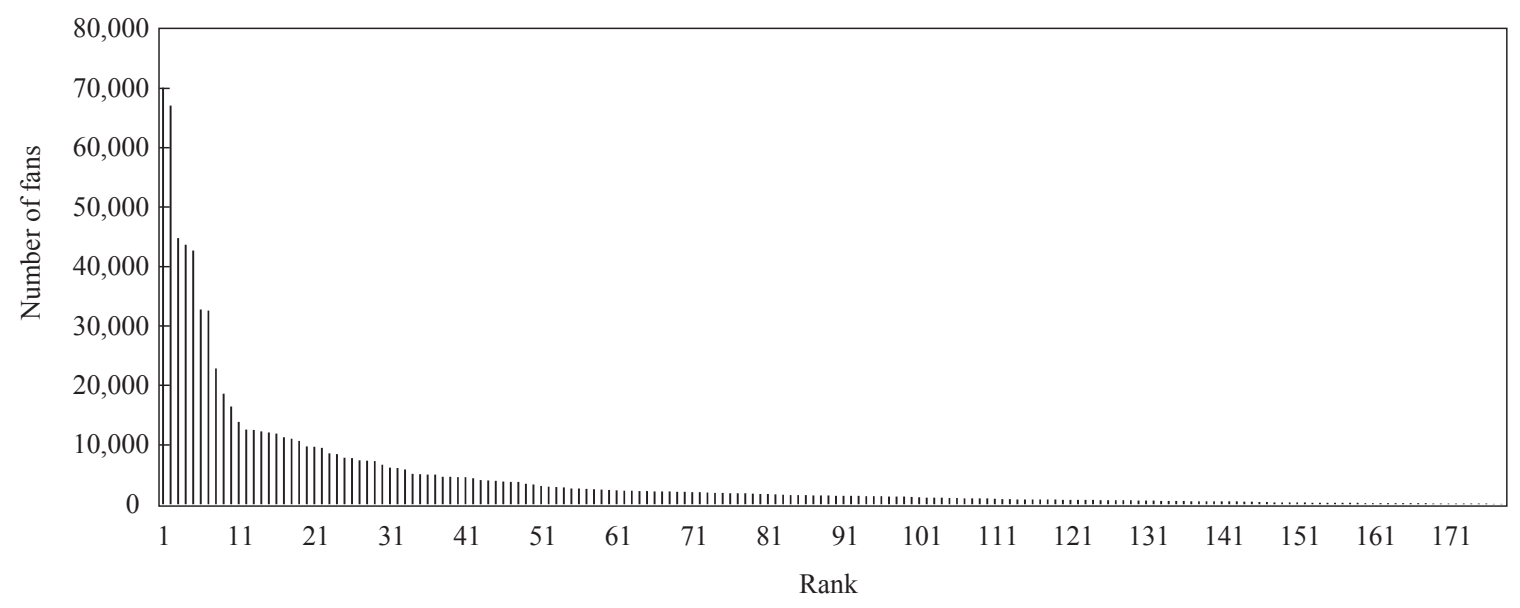

Figure 1: Number of fans of the 178 Facebook pages offering regional tourism information 


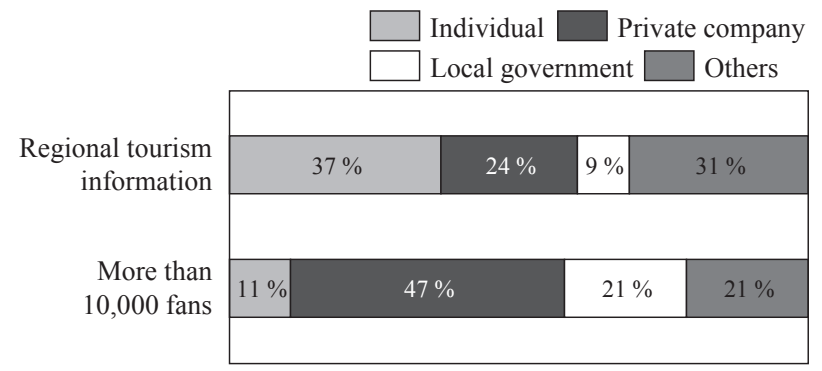

Figure 2: Management of Facebook pages offering regional tourism information

incorporated nonprofit organizations (NPOs), and volunteer groups. Figure 2 (bottom row) shows the classification of the management of Facebook Pages with more than 10,000 fans among the 178 pages. Considering all the Facebook Pages offering regional tourism information, more than $30 \%$ of the pages are managed by individuals, as shown in Figure 2 (top row); however, only $11 \%$ ( 2 pages) of Facebook Pages with more than 10,000 fans are managed by individuals, as shown in Figure 2 (bottom row).

For comparison the Facebook Pages registered in sport/ recreation/activity category of Facebook navi were examined. There are 68 pages registered in that category. Among the 68 pages, the 67 pages are Japanese pages, and 8 of the 67 pages with more than 10,000 fans. Figure 3 shows the classification of the management of the pages registered in that category. The percentage of private companies was higher in the pages in Figure 3 than in the pages offering regional tourism information (Figure 2), while the percentage of individuals and local governments was less.

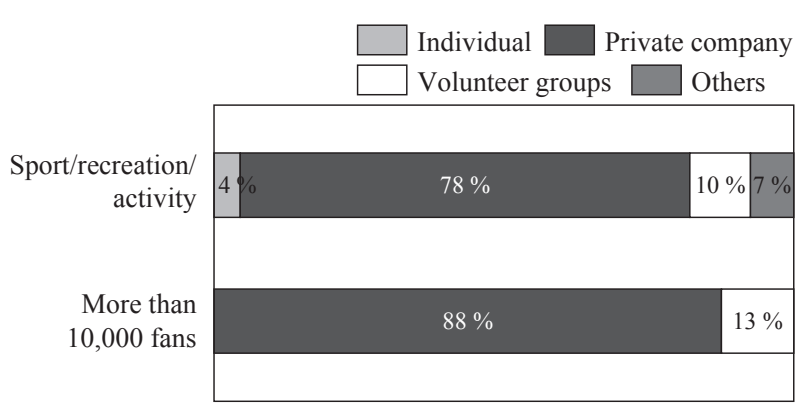

Figure 3: Management of Facebook pages registered in sport/ recreation/activity category

\subsubsection{Facebook pages with high attractiveness}

Table 1 shows a summary of 19 Facebook Pages with more than 10,000 fans. Facebook Pages for various areas from Hokkaido to Okinawa attract many fans, although 2 pages on Yokohama are also included in the list. For these 19 Facebook Pages, posts, the presence or absence of photo and video images, the presence or absence of links to other homepages, the number of "Likes" for each post, the number of "Shares" for each post, and user comments were obtained between January 1 and De- cember 31, 2015, by Graph API.

Engagement rate is an index for evaluating the attractiveness of pages on SNSs. The conventional engagement rate of Facebook Pages is given by

Conventional engagement rate $=($ Number of "Likes" + Number of comments + Number of "Shares" of the post)/Number of fans.

However, conventional engagement rate defined in this way decreases as the number of fans increases [Facenavi, 2014]. Therefore, Facebook, Inc. defined a new engagement rate as

New engagement rate $=($ Number of "Likes" + Number of comments + Number of "Shares" + Number of people who have clicked on the post)/Number of reaches.

This was released in January 2015 or later but the exact date of introduction was not publicized. The new engagement rate cannot be calculated by third parties, other than the management, because the reach count and click count of the page are used in the calculation. Therefore, in this study, the conventional engagement rate calculated using eq. (1) was used to determine the engagement rate per fan in Table 1. According to the Facebook Engagement Survey 2014 [Facenavi, 2014], the mean engagement rate of Facebook Pages with $\geq 10,000$ and $<50,000$ fans is $1.996 \%$ and that of Facebook Pages with $\geq 50,000$ and $<100,000$ fans is $1.499 \%$. The mean engagement rate of Facebook Pages in the travel/leisure category is $1.56 \%$ (mean number of fans: 30,642).

The number of Facebook Pages with engagement rates of $<1$ $\%, \geq 1$ and $<2 \%, \geq 2$ and $<3 \%, \geq 3$ and $<4 \%$, and $\geq 8$ and $<$ $9 \%$ per fan is 5, 2, 4, 7, and 1, respectively. The Facebook Page on Shirakawa-go accepts posts from users, and the number of posts is extremely high. The engagement rate per post is small, as is the engagement rate per fan.

In this study, both the engagement rate per fan and the number of fans are used as indices of attractiveness. Three Facebook Pages with an engagement rate of $\geq 3 \%$ and a large number of fans, namely, the Facebook Pages of "Kyushu Tourism Information", "Akita Vision", and "Yokohama Tourism Information", were selected from Table 1 as Facebook Pages with high attractiveness to be analyzed.

\section{Analysis of user comments}

In this section, the user comments on the pages with high attractiveness were classified into ten types to clarify the feelings that cause users to post comments.

\subsection{Analysis method}

For the Facebook Pages of "Kyushu Tourism Information", "Akita Vision", and "Yokohama Tourism Information", user comments collected over a period of one year (2015) were analyzed to avoid seasonal bias. 


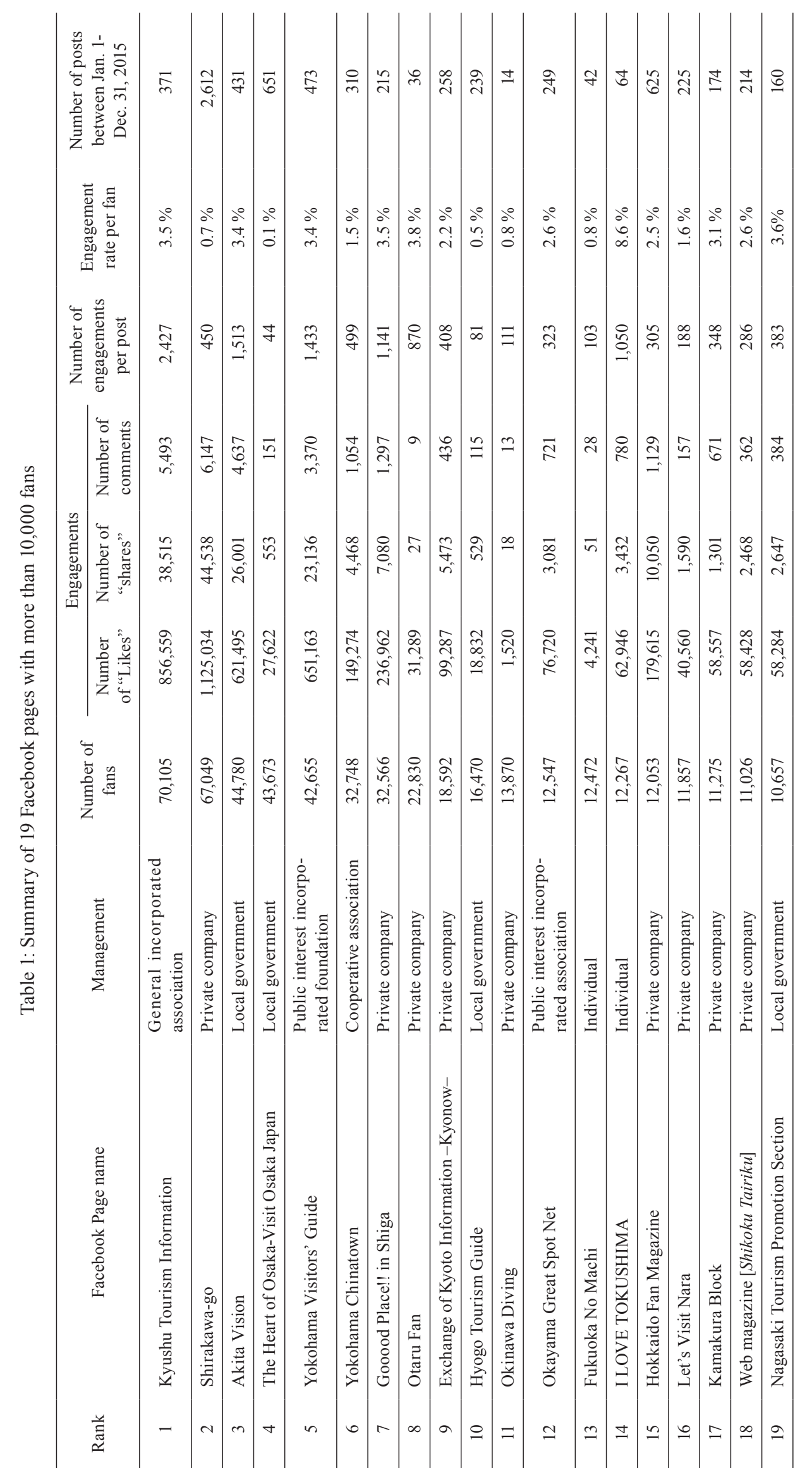


Table 2: Examples of classifications of feeling of user comments

\begin{tabular}{llc}
\hline & \multicolumn{1}{c}{ User comment } & Classification \\
\hline Example 1 & I will go there next week $\left({ }^{\wedge}{ }^{\wedge}\right)$. I can’t wait. & Joy \\
\hline Example 2 & It's a waste of electricity. & Anger \\
\hline Example 3 & I can’t visit to take photos because of work this year (T_T) & Sadness \\
\hline Example 4 & I'm worried about fainting because of the high temperature. & Fear \\
\hline Example 5 & I love Yokohama! & Liking \\
\hline Example 6 & Oh, my god. I can't take holidays during silver week because of work. & Disgust \\
\hline Example 7 & It's a beautiful night scene!!! & Sensation \\
\hline Example 8 & I feel relaxed. I'll enjoy the night scene when I go back to my hometown. & Ease \\
\hline Example 9 & 5000, wonderful! & Surprise \\
\hline Example 10 & It's really beautiful!! I'd like to visit there and ride it! & Sensation, \\
\hline Example 11 & I will share the page. & Liking \\
\hline Example 12 & Can I get it in Tokyo? & "Share" "Others" \\
\hline
\end{tabular}

First, engagement rates of all the posts for the three pages in 2015 were calculated. We read all the user comments for the posts with the top 100 engagement rates (hereafter, user comments for the top 100 posts) and the user comments for the posts with the lowest 100 engagement rates (hereafter, user comments for the lowest 100 posts) and classified the user comments in accordance with the feelings that caused users to post comments. For this classification, ten feelings in the Dictionary on Expression of Feeling [Nakamura, 1993]; namely, "joy (pleasure)", "anger (unpleasantness)", "sadness (crying)", "fear (apprehension)", "shame (humiliation)", "liking (longing, nostalgia)", "disgust (loathing, regret)", "sensation (inspiring, excitement)", "ease (calm)", and "surprise (amazement)" were used. Table 2 shows examples of user comments classified into these ten feelings. Examples 1-9 are classified as one of the ten feelings. When multiple feelings are included in one comment, as in example 10, the user comment is classified as multiple feelings. Comments including the intension of "share" in the sentence are classified as "share". The comments that do not belong to any of the ten feelings are classified as "others". Stamps without any comments are classified as "stamp".

\subsection{Analysis results}

Figures 4 and 5 show the classifications of feelings underlying the user comments for the top 100 posts and those underlying the user comments for the lowest 100 posts, respectively. The total number of user comments for the top 100 posts classified as one of the feelings, "share", "stamp", or "others" is 6,924 . The percentage of "liking (longing, nostalgia)" was the highest $(25.9 \%)$, followed by "sensation (inspiring, excitement)" (17.9\%). The total number of user comments for the lowest 100 posts classified as one of the feelings, "share", "stamp", or "others" is 1,200. The percentage of "liking (longing, nostalgia)" was the highest (29.8\%), followed by

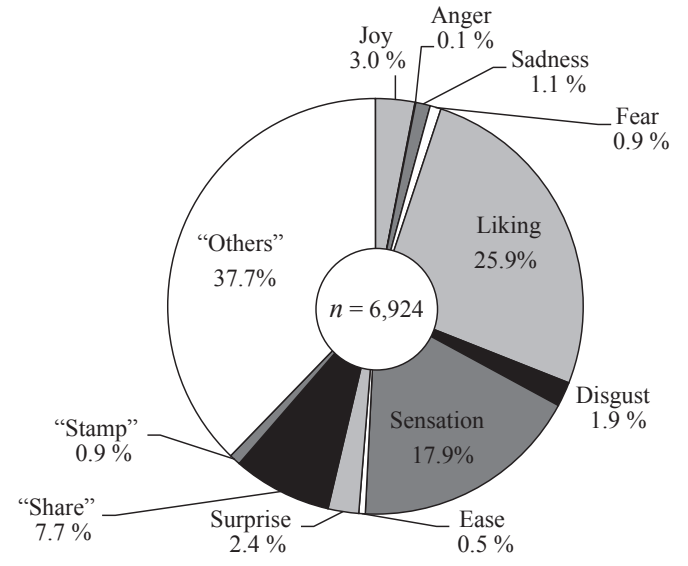

Figure 4: Classification of feelings of user comments for the top 100 posts

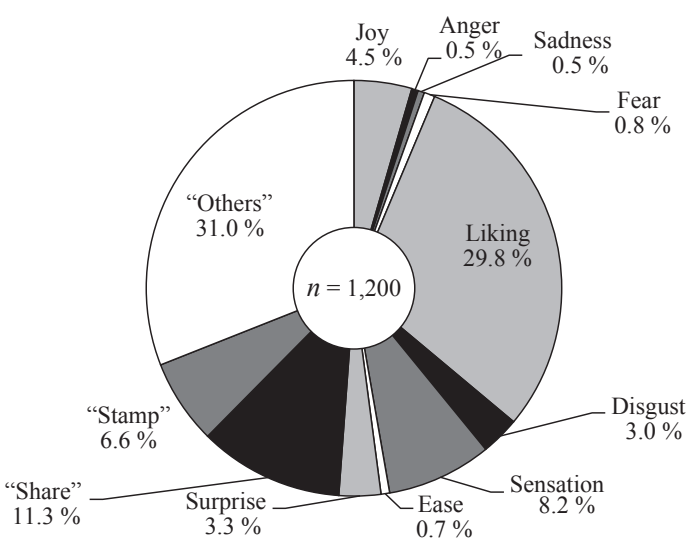

Figure 5: Classification of feelings of user comments for the lowest 100 posts 
"share" (11.3\%) and "sensation" (8.2\%). There are no user comments for either the top or the lowest 100 posts classified as "shame".

The numbers of the user comments for the top and lowest 100 posts in each feeling classification were compared. As shown in Table 3, we developed a $2 \times 2$ contingency table to summarize the number of user comments classified as one of the feelings and the total number of user comments classified as other feelings, "share", "stamp", and "others", to carry out Fisher's exact test. A contingency table was developed for each feeling in the test. Table 4 shows the summary of the data and results. A significant difference was observed between the user comments for the top and lowest 100 posts for six feelings, "share", "stamp", and "others". The underlines in Table 4 indicate which of the top or lowest 100 posts has a higher number of user comments than the

Table 3: Contingency table summarizing the number of particular feelings for the user comments for the top and lowest 100 posts

\begin{tabular}{lcc}
\hline & Top & Lowest \\
\hline Feeling X & $\mathrm{a}$ & $\mathrm{b}$ \\
Feelings other than feeling X & $\mathrm{c}$ & $\mathrm{d}$ \\
\hline
\end{tabular}

Notes: a The number of user comments for the top 100 posts classified as feeling X

b The number of user comments for the lowest 100 posts classified as feeling $\mathrm{X}$

c The number of user comments for the top 100 posts classified as feeling other than $\mathrm{X}$

$\mathrm{d}$ The number of user comments for the lowest 100 posts classified as feeling other than $\mathrm{X}$

Table 4: Number of comments for the top and lowest 100 posts classified into each feeling category and the results of Fisher's exact test

\begin{tabular}{lrrc}
\hline Feeling & Top & Lowest & $p$ value of Fisher's exact test \\
\hline Joy & 211 & $\underline{54}$ & $0.013^{*}$ \\
Anger & 5 & $\underline{6}$ & $0.002^{*}$ \\
Sadness & $\underline{78}$ & 6 & $0.045^{*}$ \\
Fear & 59 & 10 & 1.000 \\
Liking & 1,793 & $\underline{357}$ & $0.006^{*}$ \\
Disgust & 133 & $\underline{36}$ & $0.021^{*}$ \\
Sensation & $\underline{1,237}$ & 98 & $0.000^{*}$ \\
Ease & 35 & 8 & 0.515 \\
Surprise & 165 & 39 & 0.088 \\
"Share" & 533 & $\underline{135}$ & $0.000^{*}$ \\
"Stamp" & 62 & $\underline{79}$ & $0.000^{*}$ \\
"Others" & 2,613 & $\underline{372}$ & $0.000^{*}$ \\
\hline
\end{tabular}

Notes: Fisher's exact test: $* p<0.05$

The underlines indicate which of the top or lowest 100 posts has a greater number of user comments than the expected value. Also, a significant difference was observed between the user comments for the top and lowest 100 posts. expected value for the classification with significant difference.

\subsection{Tendency of user comments classified as each feeling}

The number of user comments for the top and lowest 100 posts classified as "joy" is small. The content of comments is an expression of gratitude, such as "thank you for the information on $\mathrm{xxx}$ ", "I'm looking forward to attending $\mathrm{xxx}$ " for the announcement of an event, and "I'm looking forward to eating $\mathrm{xxx}$ " for seasonal food. A significant difference was observed between the top and lowest 100 posts. For the lowest 100 posts, the comments of users related to the management, such as "Thank you for your continued help" and "We would appreciate your continued cooperation" increases the number of posts.

The number of user comments for the top and lowest 100 posts classified as "anger" is small. A significant difference was observed between the two. For the lowest 100 posts, most of the user comments classified as "anger" point out mistakes of contents and timing of posts. There are few user comments expressing anger and unpleasantness.

The number of user comments for the lowest 100 posts classified as "sadness" is small. For the top 100 posts, most of the user comments classified as "sadness" express sadness that they cannot visit a place because of work despite a desire to do so or that photos of their hometown cause a longing to return.

The number of user comments for the lowest 100 posts classified as "fear" is small. Examples of the user comments for the top 100 posts include concern regarding going to a place introduced in the post and the fear of unconventional designs and ideas in the post.

There are no user comments classified as "shame" for either the top or the lowest 100 posts.

The number of user comments classified as "liking" is the largest among the user comments for both the top and lowest 100 posts. Although a significant difference was observed between the two, the content of comments is an expression of liking, such as "I like xxx hot spring" and "I love xxx!", the expression of longing, such as "I would like to visit xxx once in the future", and the feeling of nostalgia because of overlapping old memories with the post. People often express liking when they read posts related to their past experience and knowledge, such as a previously eaten food, a place they would like to visit in the future, and memories of childhood.

The user comments for the top and lowest 100 posts classified as "disgust" mostly express feelings of regret, such as "I would like to go but I cannot". Only a few user comments express undesirable and unfavorable feelings. The number of user comments for the low 100 posts classified as "disgust" tended to be large. It is thought that the cause is the comments express feelings of regret against information of event cancellations.

The number of user comments for the top 100 posts classified as "sensation" tended to be large, and a significant difference was observed between users comments for the top and lowest 100 posts. Among the user comments for the top 100 posts, the 
number of user comments classified as "sensation" is the second most numerous after those classified as "liking". Users are moved by photos of beautiful scenes and excited by photos of delicious-looking food for both categories of posts.

The number of user comments for the top and lowest 100 posts classified as "ease" is small. Users feel relief or healed upon viewing the photos posted.

Regarding "surprise", for user comments on the top 100 posts, users are surprised at the scale and impact of photos or amazed by the beauty of photos. User comments for the lowest 100 posts express surprise because they found unexpected content in the post, such as "I never imagined that such a place existed there".

Some users making comments classified as "share" feel empathy with the post and express their intent to share the post. However, users simply click the share button (a simple comment expressing the intension as is often the case). A significant difference was observed between the user comments for the top and lowest 100 posts. The number of user comments classified as "share" is greater for the lowest 100 posts. It is thought that users related to the management and the fans of the Facebook Page share posts regardless of their feelings toward the contents of posts.

The number of user comments for the top and lowest 100 posts classified as "stamp" is small. A significant difference was observed between the two, and the number of user comments for the lowest 100 posts classified as "stamp" tended to be larger.

The number of user comments classified as "others" is largest for both the top and lowest 100 posts. Examples of user comments include questions, such as example 12 in Table 2, reports of past experience, such as "I have visited there" and "I ate it yesterday", and expressions of intent and plans, such as "I will visit there next" and "I will go to eat there again this year". We suggest that the comments reporting past experiences are triggered by the feeling of liking the post. The comments expressing intent and plans are possibly triggered by the feeling of sensation (users are moved or excited about the post) and the feeling of joy. However, we cannot detect the true feeling of users, and we classified user comments that do not include the direct expression of feelings as "others" in this study.

\subsection{The page with high engagement rate}

The engagement rate of the Facebook Page "I Love Tokushima" in Table 1 is extremely high $(8.6 \%)$. This page is managed by individual. The number of posts per year is 64 , which means an annual posting frequency of 1.2. Figures 6 shows the classifications of feelings underlying the user comments for the posts with an engagement rate of $\geq 4 \%$. The percentages of "Sadness", "Surprise" and "Others" were higher than classifications of feelings of the user comments for the top 100 posts (Figure 4), while the percentage of "Sensation" was less.
The user comments classified as "sadness" often express sadness because nostalgic buildings have been lost or the posts on local cuisine bring to mind memories of a departed grandmother. Comments classified as "surprise" indicate the surprise of users on discovering, for the first time, that a common custom in Tokushima prefecture does not exist in other prefectures by reading a post, or their shock on knowing that the popular artwork in front of Tokushima Station had been removed. These comments are considered to have been posted by users who come from Tokushima prefecture or who know Tokushima very well.

Comments classified as "others" are generally from users who ask questions regarding posts, post additional information, or merely express that they know the information. Among the 780 comments of "I Love Tokushima" in Table 1, 247 comments are responses to the comments of organizations. The engagement rate of 533 comments, excluding the comments of organizations, is $8.5 \%$, indicating that the users are more responsive than those of other Facebook Pages.

An individual who comes from Tokushima prefecture posts and responds to other posts on this Facebook Page. The introductory explanation of this Facebook Page is "Tokushima is an exciting place; let's boost Tokushima by talking about its attractive points!". From the comments of users, the percentage of users who come from Tokushima prefecture or who know Tokushima very well is considered to be high. From this finding, users who try to boost excitement about this area are considered to contribute to an increase in the attractiveness of the Page.

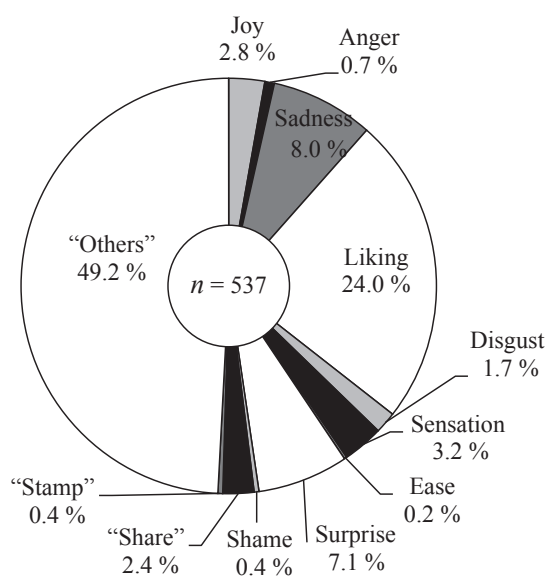

Figure 6: Classification of feelings of user comments for "I Love Tokushima"

\section{Discussion}

In this section, directions for increasing the attractiveness of Facebook Pages for those involved in the promotion of regional tourism industries are discussed by referring to actual examples of user comments for which a large number of user com- 
ments expressed the feelings of users.

\subsection{User comments for the top 100 posts classified as liking}

Example 1 is a post related to seasonal fish. Users report that the fish is delicious and describe the characteristic taste of the fish during breeding season. Example 2 is a post reporting the arrival of the season for tourist boats with kotatsu, a small table having an electric heater underneath and covered by a quilt. Comments 2-1 and 2-2 indicate that users have enjoyed this type of boat before, recommend it to others, and express their intent to experience it again. The user of comment 2-3 had experienced the boat without kotatsu and expresses a willingness to experience the boat with kotatsu this season.

Among the user comments for the top 100 posts, those classified as "liking" are the most numerous. To increase the attractiveness of Facebook Pages for tourist spots and food, it is indispensable to offer posts of famous tourist spots and food that many users like, want to visit, and experience. For well-known information (tourism resources), timely posts considering the best season to enjoy the resources will contribute to the improvement of the engagement rate through links between the information and the lifestyle and memories of users.

\section{- Example 1 Seasonal fish \\ Comment 1-1 ("liking") \\ I ate that fish. It was delicious! \\ Comment 1-2 ("liking") \\ I've eaten this fish! It had many eggs and was delicious. \\ - Example 2 Cruise on a boat with kotatsu \\ Comment 2-1 ("liking")}

The boat with kotatsu is only in winter and was quaint. It was really nice $\left({ }^{\wedge}-\wedge\right) /$ !

Comment 2-2 ("liking")

We ate steamed eel after enjoying a boat with kotatsu!! I'd like to visit again.

Comment 2-3 ("liking")

I visited there about 5 years ago because it's my husband's hometown $\left(\wedge^{\wedge} \mathrm{O}^{\wedge}\right) /$.

It was December, but the boat didn't have a kotatsu. I'd like to try it when I visit again $\left(\mathrm{o}^{\wedge \wedge} \mathrm{O}\right)$.

\subsection{User comments for the top 100 posts classified as sensa- tion}

Example 3 is a post related to the illumination of the buildings and gardens of temples and shrines of a certain region. Users posted comments 3-1 and 3-2 because they were moved by the beautiful photos, although it is not clear whether the users actually had visited the place or not. The user posting comment 3-3 was moved by the beautiful photos and posted a comment although the user had not visited the place.

The user comments classified as "liking" were mostly posted in response to objects that users already knew, whereas the user comments classified as "sensation" were posted by users who were moved or excited by the photos regardless of their previous knowledge. This finding suggests that the content and quality of the attached photos are important and that posting of photos that may induce sensation and excitement in users is effective when posting information (tourism resources) on sites that people may not be aware of.

- Example 3 Illumination of buildings and gardens of temples and shrines

Comment 3-1 ("sensation")

It's really beautiful!

Comment 3-2 ("sensation")

The illumination of a temple in Fukuoka prefecture is beautiful.

Comment 3-3 ("sensation")

It's wonderful. I've been there once before, but I didn't know that it was such a beautiful and wonderful place.

\subsection{User comments for the lowest 100 posts classified as lik- ing}

Example 4 is a post related to local sweets. From comments 4-1 and 4-2, we can see that users feel nostalgia for their favorite sweets. In contrast, comments 4-3 and 4-4 indicate that the sweets are not famous; only a small number of people know about the sweets. Example 5 is a post related to a local restaurant. From the post and comments 5-1 and 5-2, it is clear that the users know the restaurant introduced in the post and agree on its attractiveness. From comments 5-3 and 5-4, it is clear that the users would like to visit the restaurant and eat the dishes described in the post.

Among the user comments for the lowest 100 posts, the number of comments classified as "liking" was the largest (357). The users who have eaten the sweets or visited the restaurant before, as shown in Example 4 and 5, are thought to feel empathy for the posts and make comments because of a feeling of nostalgia and the memory of the food and service, although users who did not know the contents of the posts showed no interest in and did not respond to the posts. In addition, users related to the region are interested in the posts because information new to them is provided in the posts.

According to the results of the questionnaire survey on tourism targeting local governments all over Japan [Han, 2016], $95.9 \%$ of the local governments answered that they are endeavoring to attract tourists. Regarding the presence of organizations, other than local governments, that make efforts to attract tourists, $89.3 \%$ answered that there are such organizations. They include tourist associations (80.8\%), chambers of commerce and industry (43.7\%), local residents' organizations (29.2\%), NPOs (27.2\%), hotel associations (15.8\%), and others $(12.8 \%)$. Local residents are involved in various efforts to attract tourists, including "conservation of streetscape by 
residents", "efforts to improve the local community that residents are proud of", "establishment of resident-led organizations to attract tourists", and "interaction between tourists and local residents". As explained in Section 3.4, the Facebook Page "I Love Tokushima" is vitalized by involving those who come from Tokushima prefecture. It is expected that Facebook Pages offering regional tourism information will be more vitalized by involving those who come from the area or the local residents.

Therefore, the posts about places and foods familiar to the local people, even though not famous, can attract a certain amount of responses from users, leading to an increase in the attractiveness of Facebook Pages.

\section{- Example 4 Local sweets Comment 4-1 ("liking")}

I love the sweets! This reminds me of the sweets made by my mother.

Comment 4-2 ("liking")

It brings back old memories(*^^*). I want to eat it again!

Comment 4-3 ("others")

I grew up in Akita, but don't know these sweets.

Comment 4-4 ("others")

I don't know them, either.

- Example 5 Local restaurant

Comment 5-1 ("liking")

I've frequently visited this restaurant! The hamburger, rice omelet, and demiglace sauce there are delicious!

Comment 5-2 ("liking")

I loved the dishes $(\geq \square \leq)$

Comment 5-3 ("liking")

They look delicious. I want to eat them.

Comment 5-4 ("liking")

I'd like to visit this restaurant!

\section{Conclusion}

In this study, we carried out an analysis of the feelings expressed in user comments on Facebook Pages with many fans offering regional tourism information, and clarified the feelings of the users who posted the comments. As a result, the number of comments classified as "liking" or "sensation" was high. We pointed out the following: for well-known tourism resources, timely posts considering the best season to enjoy these resources will contribute to an improvement in the engagement rate. In contrast, for tourism resources with low recognition, posting of photos that may generate emotion and excitement in users is effective. We also pointed out that posts involving those who come from the area and residents are effective.

Compared with websites, Facebook Pages can be easily started and have no startup costs. Therefore, the number of pages managed by individuals is large. When focusing on Facebook Pages with many fans, the percentage of Facebook Pages managed by individuals is small; the Facebook Pages managed by organizations such as regional tourist associations and companies offering regional tourism information are the mainstream. However, such pages are not always actively accessed by many visitors. The points pointed out in this paper may be useful for increasing the attractiveness of Facebook Pages.

In this study, increasing the attractiveness of Facebook Pages among Japanese was targeted. In future studies, inbound tourists utilizing Facebook Pages will be surveyed to examine what measures attract such tourists.

\section{Acknowledgements}

This study was supported by JSPS KAKENHI Grant Number $15 \mathrm{~K} 00476$.

\section{References}

Comnico inc. (2014). Getting fans! Know-how of posting on Facebook. Shoeisha (in Japanese)

Facebook (2017). Statistics of facebook. https://newsroom. fb.com/company-info/.

Facenavi (2014). Facebook engagement survey 2014. http://facebook.boo.jp/facebookengagement-survey-2014.

Han, J. (2016). A report on the present status and impediments to tourism-based community development: the perspective of municipalities. Ritsumeikan Journal of Asia Pacific Studies, Vol. 34, No. 14, 170-184. (in Japanese)

Instagram (2017). Statistics of instagram. https://instagrampress.com/.

Lee, W. and Paris, C. M. (2016). How your emotions on Facebook can drive your attitudes and intentions to go to the special event? Tourism Travel and Research Association: Advancing Tourism Research Globally, 17.

Line (2017). January-December 2016 business report. http:// p.sokai.jp/3938/report/. (in Japanese)

Ministry of Internal Affairs and Communications (2015). 2015 white paper on information and communications in Japan. http://www.soumu. go.jp/johotsusintokei/whitepaper/ja/h27/ pdf/. (in Japanese)

Nakamura, A. (1993). Dictionary on expression of feelings. Tokyodo Shuppan. (in Japanese)

Ohara, S., Kajiyama, T., and Ouchi, N. (2015). Extraction of characteristics of photos to increase the engagementrate of facebook pages of companies łanalysis of photos of products of fast-food companiesł. IEICE Transactions, A J98-A(1), 41-50. (in Japanese)

Sabate, F., Berbegal-Mirabent J., Canabate, A., and Lebherz, P. R. (2014). Factors influencing popularity of branded content in facebook fan pages. European Management Journal, Vol. 32, No. 6, 1001-1011.

Saito, S. (2014). Facebook marketing [Business Technique] technique of obtaining valuable "Like". Shoeisha. (in Japanese)

Sawada, A., Yoshida, T., and Murakami, K. (2016). Factors behind increasing attractiveness of tourism-related facebook 
pages. Proceedings for the 13th Workshop of the Society for Tourism Informatics, 17-20. (in Japanese)

Twitter (2016). Twitter usage/company facts. https://about.twitter.com/ja/company.

Wilson, R. E., Gosling, S. D., and Graham, L. T. (2012). A review of facebook research in the social sciences. Perspectives on Psychological Science, Vol. 7, No. 3, 203220.

(Received October 15, 2017; accepted November 2, 2017) 